\title{
Performance Measures of the Academic Managerial Spine
}

\author{
Nitza Davidovitch, PhD \\ Eyal Eckhaus, PhD \\ Ariel University, Israel
}

Doi:10.19044/ejes.v7no4a7 URL:http://dx.doi.org/10.19044/ejes.v7no4a7

\begin{abstract}
This pioneering study is the first to explore the research output of faculty members that constitute the managerial spine of an academic institution. We related to the managerial spine on four levels of seniority and responsibility at the institution: President, Rector, and Deans; heads of department; faculty members on academic committees and leaders of the program; heads of study tracks and deputy heads of department. Age and gender are also explored.

Empirical data on article citations and teaching surveys were gathered for 88 senior faculty members in a case study of an academic institution in which faculty members occupy or occupied a senior management role. It is evident from the research findings that the first group has the highest h-Index, followed by the second group, and finally, the third and fourth groups. With regard to gender, no conclusions can be reached, as almost all those in this group are men. With regard to age - the group of retirees had the highest output.

The fact that the managerial spine has the highest research output is capable of illuminating the managerial profile of the academic institution. Academic management is unique for being two-headed: with a separation between academic management and administrative management. The research findings lead to the question of whether and to what degree are the considerations taken into account in the decisions of policymakers at the institution academic or are administrative considerations dominant.
\end{abstract}

Keywords: Performance Measures, Management, Academy.

\section{Introduction}

The academic management orientation of institutions of higher education

The academic establishment resembles the church establishment not only in the traditional designations of senior positions - Chancellor, Rector, 
Provost, Dean - but also in the basic managerial model originating from the Middle Ages, which has since mostly remained unchanged. It has been designated "shared governance" - meaning separation between administrative management and academic management. This model is based on the admirable desire to protect the academic freedom of those who deal with contents and on the wish to release them from concerns pertaining to constant management issues. Some claim (Almog \& Almog, 2020) that the result is a state of "organized disorder" that is almost unparalleled in the modern world (Apkariana, Mulligan, Rotondi, \& Brint, 2014).

The academic institution is usually headed by the President, who is also the head of the administrative division (President, Chief Executive, Chancellor, Vice-Chancellor, Principle), where the role of the President is merely symbolic. Politicians, military personnel, legal personnel, and other "formers" are appointed to this position. In a small number of institutions, mainly in Australia where the post was originally kept for a "visitor", and in New Zealand, there is a symbolic role above the church president (Almog \& Almog, 2020). When the university contains several campuses, the Chancellor is often the general director of the entire complex, where each campus has a separate president. In countries such as France, Germany, and Poland, the most senior government representative is the symbolic president of several institutions in the same district, which he does not manage in practice. In all versions where the President is a symbolic figure, the Rector is the actual head of the institution.

A comprehensive survey of the features of university and college presidents in the US, held by the American Council on Education in 2017, identified three interesting characteristics (Almog \& Almog, 2020):

1. Age - The average age of the presidents was 62 - ten years more than it was 30 years ago. The reason might be the rise in life expectancy. Still, it is more probably related to the general ageing of academic faculty members and the fact that less young people strive for a managerial career in academia.

2. Gender- The proportion of women among all presidents was approximately lim30\% (Almog \& Almog, 2020).

3. The management feature - The proportion of presidents who came from a minority background was $32.17 \%$ in most institutions, where the President is not merely a symbolic figure, he is in charge of fundraising, budget management, strategic planning, and administrative appointments. He is appointed for a set period and, as stated, is considered the most senior figure in the institution although not responsible for academic management. Under the President are deputies appointed in charge of specific administrative areas such as 
finance, personnel, marketing and public relations, and they comprise the operational management of the university (Nelson, 2014).

The academic division of the institution is headed by the Rector - a term derived from the Latin word and borrowed from the Catholic church. In Spain he is called regere, ruler. In Scotland, it was customary to call him "Lord Rector", in the US and Canada "Magnific Rector", "Vice-Chancellor" (Provost, in England and Ireland), in liberal arts colleges - Deputy Vice Chancellor. In Australia, the Rector is sometimes called "Dean of Faculty" or "Dean of College". In contrast to the President, who is elected by the governing council (usually a search committee searches for suitable candidates), the Rector is elected by all faculty members (for instance in Germany) or by their representatives (these are usually members of the senate and sometimes, for example in Italy, by a designated body that represents the faculty and the students). In some countries (such as the Czech Republic) the chosen Rector is subject to confirmation by the authorities (Nelson, 2014).

In almost all institutions, the Rector is in charge of the professional dimension of the academic work - both research and teaching, including appointments and promotions. His authority changes according to the institution, as does his status in the organization. Still, he is usually above the faculty deans, heads of the professional schools, and sometimes also heads of the intra-university colleges (in the case of a large institution with branches), as well as the student dean, research dean, and library managers (Almog \& Almog, 2020). The Rector also heads the senate and the institutional appointments committee and is a member of all the university's managing bodies. In a large number of institutions, the Rector is, in fact, the secondhighest-ranking official in the organization and also called senior vice president for academic matters.

Organizational structures that have separate authorities for administration and content are not rare and even operate well in many places. For instance, theatres that have an artistic director and a general director, or schools that have a pedagogical principal and an administrative principal. However, these have a clear hierarchy where one person heads the system and has full decision authority. In institutions of higher education, in contrast, the management model is not hierarchic. Although the President formally leads the institution, in practice, his authority is very limited regarding the core issues of the organization, i.e., research and teaching (including study programs, academic appointments and promotions). The Rector and the President operate concurrently, and their collaboration is based to a large degree on the goodwill and personal chemistry (Almog \& Almog, 2020, Apkariana, Mulligan, Rotondi, \& Brint, 2014). The president is responsible of the administrative operations, and the rector is in charge of the academic 
issues. However, when the president is also an academic person, that is, has an academic background, his attitude will include academic management, while understanding academic needs.

The two-headed leadership makes it hard to maintain synergic management and in many cases, paralyze the system. When the management of a single institution is divided into two heads that are also appointed separately, this is fertile ground for conflicts of interest and interpersonal tensions. This split also makes it hard to build a vision for the organization. Strangely, the split model was originally intended to allow institutions of higher education to conduct themselves in a supplementary differential manner (on one hand scientific experts and on the other administrative experts), but in practice, most presidents of institutions of higher education around the world come from the academic world. A comprehensive survey held in the US in 2001 found that $62 \%$ of all university and college presidents came from the academic world rather than from the administrative and/or business world, wherein public institutions their rate was even higher $-77 \%$, namely, these are not managers with a proven record. In contrast, in private institutions, their proportion was "only" 56\%, and these were usually professors with personal connections who made their way to the top of the pyramid by political lobbies, personal ties, and sharp elbows (Kaplan, 2002).

Notably, while in the US the orientation is more "administrative", more "economic" - which also dictates the professional profile of the board of directors and governing council, in Europe it is more "academic" (Almog \& Almog, 2020). This fact might have significance for decision-making processes in the institution - whether stemming from academic needs or "business" motives.

\section{Managerial decentralization}

All academic institutions have a changing mosaic of disciplinary units called "faculties" (in some institutions the word "school" is used): social sciences, the humanities, exact sciences, natural sciences, engineering sciences, health sciences, educational sciences, and law. A senior faculty member heads each of the faculties called a Dean. Each is comprised of several departments headed by elected faculty members (this role can also be occupied by less senior faculty members). In addition, smaller and more focused academic settings also operate within institutions of higher education, such as laboratories, chairs, and research institutes (Eckel \& Trower, 2018).

There is seemingly no fundamental problem and even advantages to decentralization of management, delegation of authority, and its distribution, but the excessive splitting of auxiliary units has a severely detrimental impact on the functioning of academic institutions for several reasons: First of all, the disparities between the departments are at times so large (the nature of 
research and studies, the size of the budgets, the demand for studies, and more) that it is hard to apply uniform procedures, an overall policy, and a shared vision to them all. In fact, there is no other example of an organization that manages so many areas from such different content worlds concurrently. For instance, departments such as English literature and nuclear engineering, that have very little in common, can exist in the same institution and receive the same instructions and directives regarding teaching, budgets, appointments, and so on (Eckel \& Trower, 2018).

Second, although all units are subject to the same management and the same university committees, in many areas the faculties and departments receive wide managerial autonomy, for instance in managing the budget, recruiting personnel, and developing study programs. The result is a lack of coordination or weak coordination between the units in setting goals, authority, and budgets, as well as many duplicities and waste of resources (Stewart, 2016).

Third, the university structure is so split and non-hierarchic that even simple management decisions require approval and repeat approval involving endless officials and faculty members (department council, faculty council, professional committees, ad hoc committees, and others). Another problem is the professional level of the department heads and deans. Institutions of higher education have gargantuan budgets, employ an army of workers, and hold yielding assets (buildings, halls, pools, property, shares, bonds, and more) that require regular maintenance, complex financial management, and thoughtful investment. This, while a large part of the department heads and deans lack any knowledge and experience in management and finance and did not receive prior professional training. Notably, excellence in research and teaching is no guarantee of management abilities (Hearn \& Brown, 2016). In These e often conflicting skills that are rarely found in one person. It is not unusual to see a complete oaf, who can hardly manage his finances, elected department head or Dean. In many cases, the result is amateurish, often negligent management, that has a heavy price. This might explain why many institutions - that contain leading economics and business managers - accumulate giant deficits (Stewart, 2016).

Moreover, it is not rare for faculty members to be selected for management roles (by vote in the department, faculty, or senate) based on irrelevant and mainly political considerations of their colleagues. In many cases the choice is by default, i.e., the person who agreed to take on the role or "accepted the decision of the collective" and "did what was right". The appointment is often agreed in advance by the senior ranks by using iances and exchange deals, where most of the faculty members are unfamiliar with the needs of the position, the candidate's managerial skills, and all the more so his suitability for the role. They receive instruction as to who to vote for 
and comply. In any case, it is clear to everyone that very little will change (if at all) following the appointment. There are of course faculty members who do well in their managerial role, but due to the current method, this is a matter of chance (Eckel \& Trower, 2018).

Another problem with the academic management model is that senior managers resume their role as regular faculty members after three to five years in the managerial position. It may be said, of course, that there is something nice and democratic in this management rotation. Still, professionally this turnover is a disaster, reminiscent of the management problems that afflicted the kibbutzim in the communal era. First, until the new manager learns the secrets of the position, he is already on the way out. Second, the model whereby today you are my boss and tomorrow I will be yours creates contempt for the management role and avoidance of hard and painful decisions (particularly regarding promotions, cuts, and worsening of conditions) (Stewart, 2016).

Only very few survive in management positions over time, mostly not for the right reasons. In practice, in almost every academic institution, there is a small group of bigwigs who have their eye on the management positions and play a game of musical chairs. Many are mediocre scientists, for whom their political, managerial career in academia serves as compensation for lack of intellectual shine or limited scientific success. The true scientific geniuses are usually not attracted to management roles and internal politics to begin with and are invested in their spiritual world where they find their true calling. Hence, a study conducted in 2017 in the US found that only at the top research universities did the presidents have an impressive scientific record. Most of the other institutions examined were headed at the time of the study by inconspicuous scientists, of whom many had found it hard to advance in the academic ranks before being appointed to their prominent administrative role (Brint, 2018).

It is not rare for struggles between bigwigs over senior positions to create bad feelings - not only due to the ego involved but also because those selected usually represent interest groups and coalitions within the institution. Each group wants to ensure maximal control of power and influential positions to help its members with promotions, resources allocated and positions (Waldo, 1970).

It is hard to estimate when the current academic management model will cease to exist, but signs of change are already evident in the field. The financial crisis revealed problems of irresponsible management, disorder, and extreme waste in many institutions, together with weaknesses regarding control and supervision. The image of the academic institutions as bodies that are managed in a measured, thoughtful, and honest manner, as befits scientists and thinkers, is being gradually undermined. The "academic freedom" 
umbrella is providing institutions with less protection. In several countries, there are already precedents of court interventions when universities refused to allow government officials to investigate their financial conduct (Hofstadter, 1955).

The considerable financial and management credit given these institutions in the past is diminishing over time and the funding bodies governments, funds, and donors - are demanding greater involvement and transparency, including employing external advisors. Lately, organizations and associations acting to uphold government standards have been joining this demand, as has the media.

Furthermore, in many countries assessment committees have been established to examine study programs, the composition of the faculty, and the performance of faculty members, to increase $g$ the efficacy of processes and determineg proper priorities for funding research and teaching. Several reports have also been published, which provided data, interpretations, and recommendations concerning the management and funding of academic institutions (Councilt of Higher Education, 2012). Indeed, the reports were as a rule conservative and the recommendations hesitant, making do with minor corrections. Still, it may be assumed that external demands for change will become in time more assertive and frequent (Santiago, Tremblay, Basri \& Arnal, 2008).

Notably, supervision of the system of higher education has increased internationally as well. For instance, when Bosnia-Herzegovina asked to join the European Union, it was required to effect a reform in its educational system and adapt it to Western European standards (Jahic \& Rahimic, 2017). It may be assumed that in the not too distant future we will see more and more institutions combining the roles of Rector and President and appointing more professional and active boards of directors and governing councils that demand close inspection of account books and strategic plans. Lawsuits too are expected to grow. Many institutions may shift to an accountability model of management as customary in the business world; namely, professional managers overseen by professional directorates (Eckel \& Trower, 2018; Stewart, 2016).

Nonetheless, it is doubtful whether all these procedures will suffice to get institutions of higher education back on their feet. In the current state of affairs, it is doubtful whether capable managers, idealist. However, they may be, will wish to become involved in a tough situation with little chance of recuperation. What awaits them is mainly a giant deficit, faculty who protect their cheese and fight for their subsistence, Finance Ministry officials who are extremely strict, an anachronistic structure that is unsuitable for the new era, and finally also a much less sympathetic media. It is no coincidence that in recent years the rate of managers who have left their positions, namely were 
dismissed, resigned, left after one term, or did not have their term renewed, has grown (Trachtenberg, Kauver, \& Bogue, 2016). For purposes of illustration, from 2011 to 2014, 16 of the 34 presidents at top public research universities in the US resigned or were dismissed (Blumenstyk, 2015).

\section{Academic work}

The daily work of scientists in academia is comprised of five complementary activities:

A. Teaching in class, including planning and preparing lessons, checking assignments, and awarding grades.

B. Guiding students for advanced degrees (Master's, PhD, and post-doc).

C. Regular administrative and scientific work, including membership in professional and administrative committees, reviews (articles, Master's and $\mathrm{PhD}$ theses, research proposals, promotion portfolios of faculty members, and others) and sometimes also managing a track, department, or faculty.

D. Activities outside the main institution - for a fee or voluntarily - such as counseling, membership in government and public committees, collaborations with commercial bodies and media, and lectures to the wide public.

E. The most demanding task is research.

As stated, the current study is a pioneer study that is the first to examine the research output of faculty members who constitute the management spine of an academic institution. For this purpose, we divided these faculty members into four groups of seniority and responsibility at the institution:

A. President, Rector, and Deans - the most senior academic spine of an academic institution;

B. Heads of department;

C. Faculty members active on academic committees (appointment committees and others);

D. Heads of program, heads of study tracks, and deputy heads of department.

We divided each group in half (upper and lower) concerning the output relative to the $\mathrm{h}$-index.

H1. The President, Rector, and Dean group will have the highest h-index mean.

H2. The Department Head group will have the second h-index mean.

$\mathrm{H} 3$. There will be no statistical gender-related difference in any of the groups. 


\section{H-index prediction}

In addition to teaching (Davidovitch \& Eckhaus, 2019a, 2019b, 2019c), publications are the dominant output of academic researchers (Davidovitch \& Eckhaus, 2018, 2020; Eckhaus \& Davidovitch, 2019a), and have a major effect on their promotion (Eckhaus \& Davidovitch, 2019b, 2019c, 2020).

As a measure of research output, we employed Google's h-index, a widely used and studied metrics (Babineau, Fischer, Volz \& Sanchez, 2014). The h-index is a measure of both quality (number of citations) and quantity (number of publications) (Hodge \& Lacasse, 2011). That is, an h-index value of $\mathrm{X}$ is obtained if an entity has $\mathrm{X}$ publications that have all been cited at least $\mathrm{X}$ times (ibid.). Hirsch demonstrated that the h-index is highly predictive of whether a scientist will be chosen for a fellowship in a national academy or even awarded a Nobel Prize (Hirsch, 2007). The h-index is advantageous for its ability to classify an array of journals, and not only those indexed by Thomson ISI (Hodge \& Lacasse, 2011).

\section{Methodology}

Sample

Empirical data of article citations and teaching surveys were gathered from 88 senior faculty members of Ariel University who were occupying or had occupied a position. Ariel is a state University. The sample includes the entire population of managerial spine. Age ranged from 32-50 (25\%), 51-66 (45.5\%), and 67-88 (29.5\%). Twenty-nine of the respondents were females, and 59 were males. The roles were ordered in four groups of respondents, where group 1 had the highest and group 4 the lowest responsibility. Group 1 (16 people, 18.2\%) - President, Rector, and Deans. Group 2 (55 people, 62.5\%) - Department Heads. Group 3 (9 people, 10.2\%) - Appointments and committees. Group 4 (8 people, 9.1\%) - program heads, track heads, and deputy heads of department.

\section{Analysis}

We began by performing a univariate analysis to examine differences in the h-index between the four role groups, followed by a Scheffe post-hoc analysis to identify the group differences, and Duncan's multiple comparison test in order to examine differences between group 1 and the rest combined as one. Next, we performed a sensitivity analysis for group 1. In the next stages we investigated gender and age differences.

\section{Results}

Roles' h-index differences 
All hypotheses were supported. A univariate analysis was performed in order to examine differences in the h-index between the four role groups, and found a statistically significant difference among them $(F(3,70)=4.87$, $\mathrm{p}<.01)$ ). Means are displayed in Table 1 . Next, a Scheffe post-hoc analysis found a statistically significant difference between group 1 and group 2 $(\mathrm{p}<.05)$ and between group 1 and group $3(\mathrm{p}<.05)$. In Table 1 we observe that group 1 has the highest h-index mean (H1), followed by group $2(\mathrm{H} 2)$, and group 3 had the lowest statistically significant difference in the means.

Next, a Duncan's multiple comparison test was carried out to examine differences between group 1 and the rest of the groups combined as one. The test indicated a statistically significant difference between group 1 and the rest. Figure 1 illustrates the mean h-index for the groups.

\begin{tabular}{llll}
\hline Group & $\mathrm{N}$ & Mean & SD \\
\hline 1 & 14 & 25.79 & 12.10 \\
2 & 47 & 15.11 & 9.36 \\
3 & & & \\
& 8 & 11.75 & 13.76 \\
4 & 5 & 12.00 & 8.86 \\
Total & 74 & 16.55 & 11.196 \\
\hline
\end{tabular}

Table 1. H-index: groups' mean and SD.

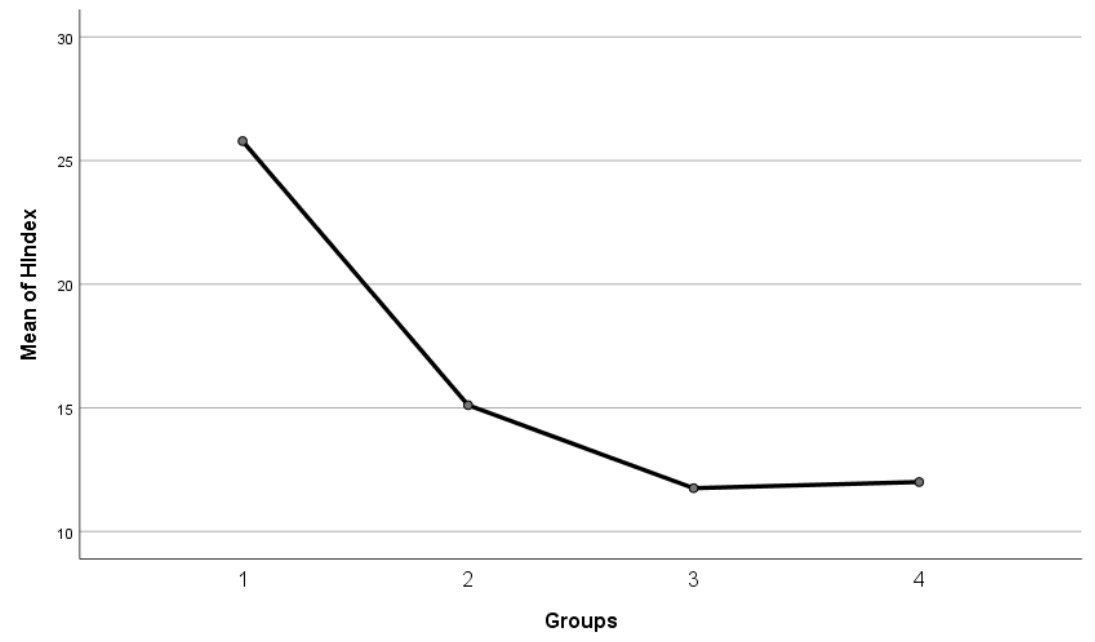

Figure 1. The mean h-index for the groups.

In Figure 1 we can observe that group 1's h-index mean is indeed much higher than the mean of the other groups. It is important to note that the calculation is based on the mean. That is, there may be some with an extreme 
amount of citations who take the entire group to their advantage. We therefore performed a sensitivity analysis.

Age

Groups 1, 3, and 4 did not have a large enough sample for age subgroups to be measured. We examined group 2; however no statistically significant difference was apparent in the age subgroups. We also explored a possible trend for the leading group 1, however apart from the four extremes it does not seem to be a trend for age subgroups. Figure 4 displays three typical age groups.

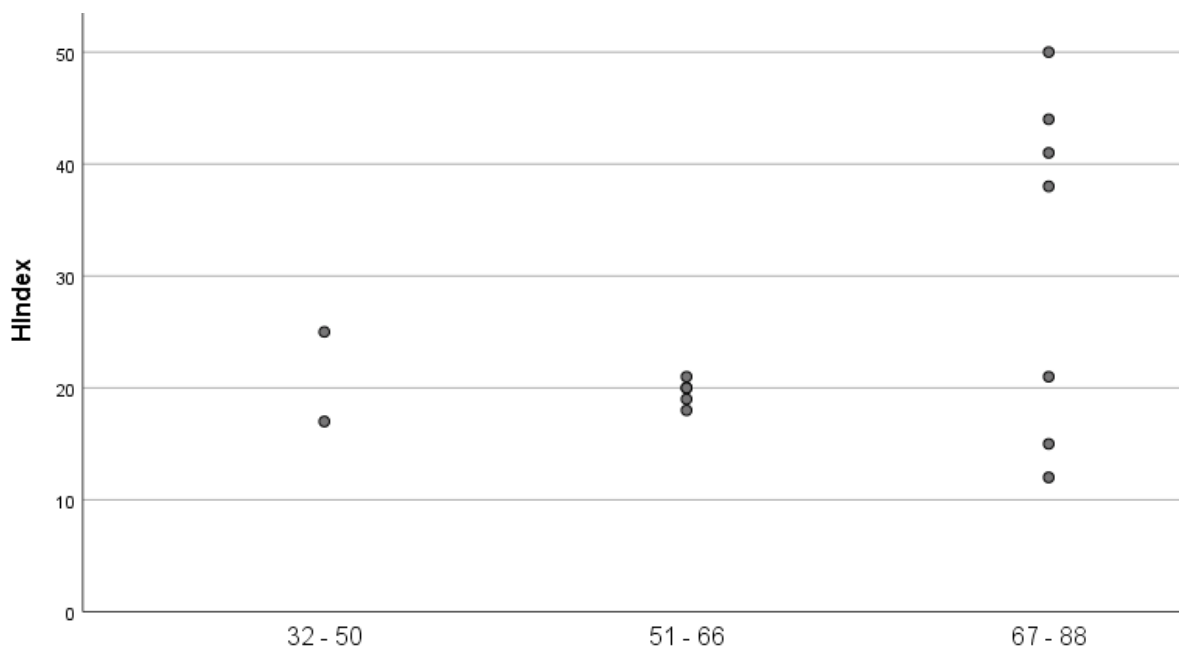

Figure 4. Division of group 1 into age groups.

\section{Gender}

We examined gender differences for each of the groups. Table 2 presents the group means; however, no statistical difference was found (H3).

\begin{tabular}{lllll}
\hline Group & & $\mathrm{N}$ & $\begin{array}{l}\text { H-Index } \\
\text { Mean }\end{array}$ & $\mathrm{SD}$ \\
\hline 1 & Female & 1 & 17 & - \\
& Male & 13 & 26.46 & 12.31 \\
2 & Female & 17 & 13.53 & 11.06 \\
& Male & 30 & 16 & 8.32 \\
3 & Female & 3 & 4.67 & 5.508 \\
& Male & 5 & 16 & 16 \\
4 & Female & 2 & 14 & 8.485 \\
& Male & 3 & 10.67 & 10.693 \\
\hline
\end{tabular}

Table 2. Gender-related h-index: mean differences between the roles. 


\section{Senate}

Since a person who occupies a role may also be a senate member, we examined the senate separately. In order to ascertain the prevalence of senate members regarding the h-index vs. non-senate members, a t-test was used. Results indicated a statistically significant difference between senate members and non-senate members in their h-index $(t=3.06, d f=72.54, p<0.01)$. Indeed, the mean of senate members $(\mathrm{M}=18.65, \mathrm{SD}=11.85)$ was higher than nonsenate members $(\mathrm{M}=11.59, \mathrm{SD}=7.62)$.

We next examined gender differences among the senate members regarding the h-index output. A t-test was used, indicating no statistically significant difference between male and female senate members. Note that none of the members in group 4 were senate members and only three people in group 3 were also senate members.

\section{Sensitivity analysis}

First, we assigned a serial number to each of the group 1 members found to be the leading h-index group and plotted the h-index output. Figure 2 illustrates the h-index output per each of the group 1 members.

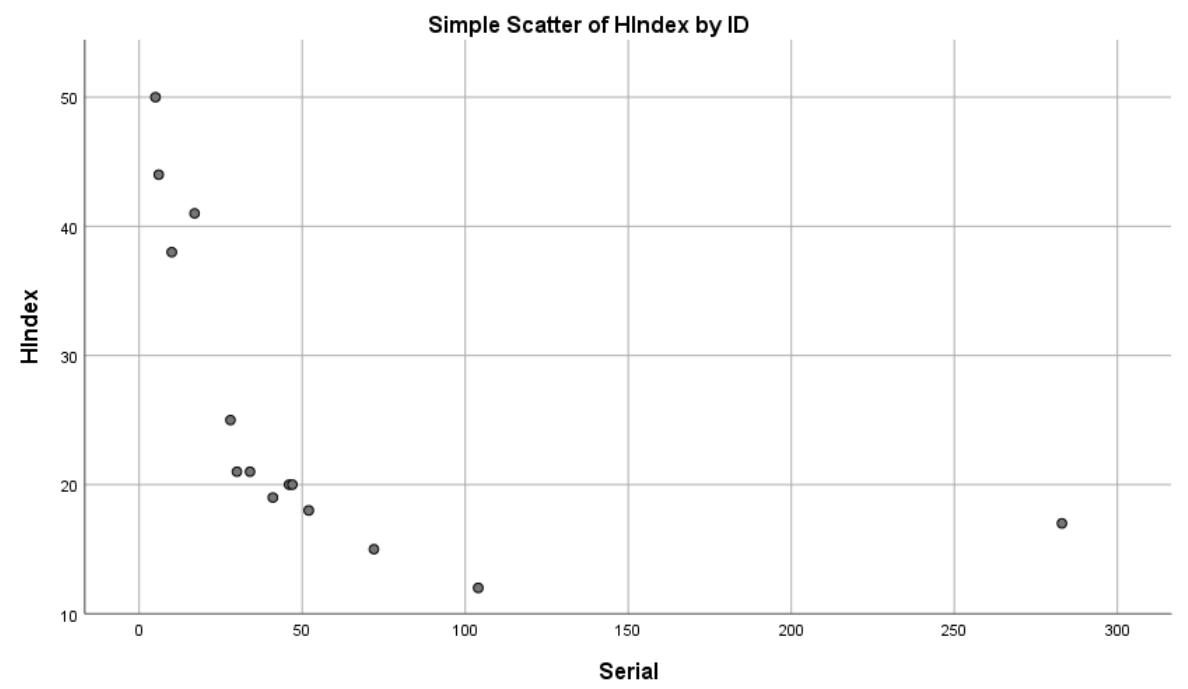

Figure 2. H-index output per each of the group 1 members.

In Figure 2, we observe that there are indeed four researchers with an extreme h-index score compared to the rest. Next, we removed the four outliers and re-examined the role differences. A univariate analysis was performed in order to examine differences in the h-index between the four roles, and a statistically significant difference was found among them $(F$ $(3,62)=4.33, \mathrm{p}<.05))$. Means are displayed in Table 3. Next, a Scheffe posthoc analysis found a statistically significant difference between group 1 and 
group 3 (p <.01). Similarly, as before removing the outliers, in Table 3 we observe that group 1 has the highest mean, followed by group 2, and the mean of group 3 has the lowest statistically significant difference. A statistically significant difference exists, however only between group 1 and group 3 .

Next, a Duncan's multiple comparison test was carried out in order to examine differences between group 1 and the rest of the groups combined as one. The test indicated a statistically significant difference between group 1 vs. the two groups 3 and 4 together. Figure 3 illustrates the mean h-index for the groups.

Table 3. H-index: groups' mean and SD.

\begin{tabular}{llll}
\hline Group & $\mathrm{N}$ & Mean & SD \\
\hline 1 & 10 & 18.80 & 3.58 \\
2 & 44 & 13.48 & 6.90 \\
3 & & & \\
& 7 & 7.29 & 5.91 \\
4 & 5 & 12.00 & 8.86 \\
Total & 66 & 13.52 & 7.07 \\
\hline
\end{tabular}

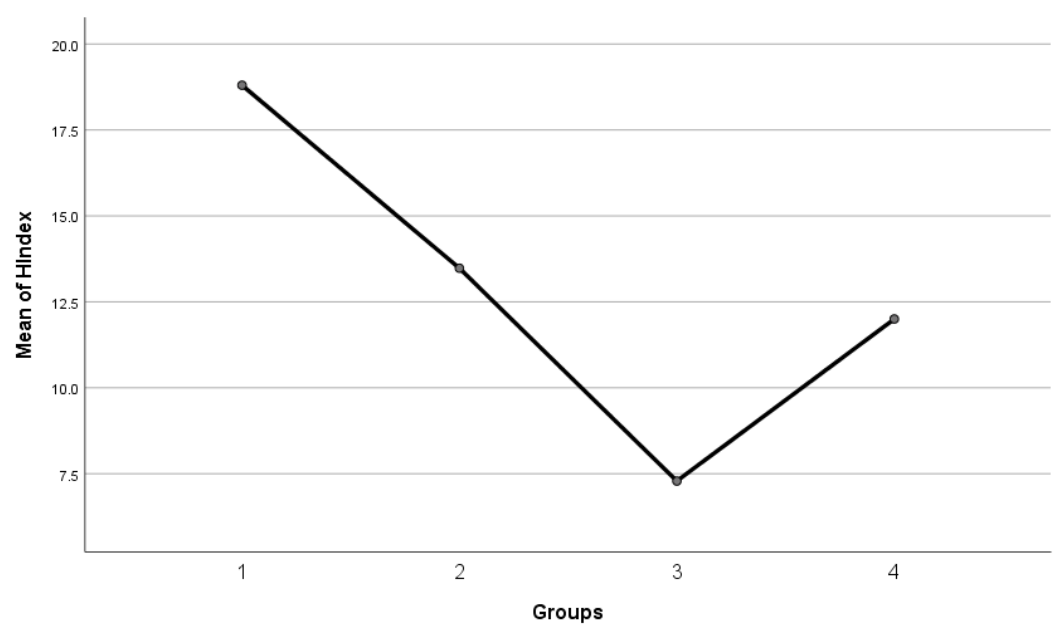

Figure 3. The mean h-index for the groups after removing outliers.

In Figure 3, we can observe the significant difference between group 1 and group 3 .

In the next part of the sensitivity analysis, we investigated age and gender differences after dividing each group into two subgroups based on the median of the h-index. Table 4 presents the $h$-index means of the upper median of all groups. Table 5 presents the h-index means of the lower median of all groups. 
Table 4. Upper median means in the h-index.

\begin{tabular}{lccccccccccccc}
\hline Age & Group 1 & \multicolumn{4}{c}{ Group2 } & \multicolumn{4}{c}{ Group3 } & \multicolumn{3}{c}{ Group4 } \\
\hline & & $\begin{array}{l}\text { Me } \\
\text { an }\end{array}$ & SD & N & Me & an & SD & N & $\begin{array}{l}\text { Me } \\
\text { an }\end{array}$ & SD & N & Mea & SD \\
& & & & & & & & & & & & \\
$32-$ & & 25. & & & 19. & 3.1 & & & & & & \\
50 & 1 & 00 &. & 8 & 25 & 1 & 1 & 9 &. & 1 & 23 &. \\
$51-$ & & 21. & & & 23. & 10. & & 14. & 4.9 & & & \\
66 & 1 & 00 &. & 9 & 78 & 06 & 2 & 5 & 5 & 1 & 20 &. \\
$67-$ & & 38. & 10. & & 23. & 8.4 & & & & & & \\
88 & 5 & 80 & 90 & 6 & 67 & 8 & 1 & 43 &. & & & \\
Tota & & 34 & 11. & 2 & 22. & 7.8 & & 20. & 15. & & & 2.1 \\
l & 7 & 29 & 83 & 3 & 17 & 1 & 4 & 25 & 65 & 2 & 21.5 & 2 \\
\hline
\end{tabular}

Table 5. Lower median means in the h-index.

\begin{tabular}{|c|c|c|c|c|c|c|c|c|c|c|c|c|}
\hline \multirow[t]{3}{*}{ Age } & \multicolumn{3}{|c|}{ Group 1} & \multicolumn{3}{|c|}{ Group 2} & \multicolumn{2}{|c|}{ Group 3} & \multicolumn{4}{|c|}{ Group 4} \\
\hline & & $\mathrm{Me}$ & $S$ & & $\mathrm{Me}$ & $\mathrm{S}$ & & $\mathrm{Me}$ & $S$ & & $\mathrm{Me}$ & $\mathrm{S}$ \\
\hline & $\mathrm{N}$ & an & D & $\mathrm{N}$ & an & D & $\mathrm{N}$ & an & $\mathrm{D}$ & $\mathrm{N}$ & an & D \\
\hline $32-$ & & 17. & & & 8.0 & 4. & & 5.0 & & & 4.5 & 0. \\
\hline 50 & 1 & 00 & & 6 & 0 & 20 & 1 & 0 & . & 2 & 0 & 71 \\
\hline 51 & & 19. & 0. & & 6.9 & 4. & & 1.5 & 0. & & & \\
\hline 66 & 4 & 25 & 96 & 12 & 2 & 21 & 2 & 0 & 71 & & & \\
\hline $67-$ & & 13. & 2. & & 11. & 3. & & 5.0 & & & 8.0 & \\
\hline 88 & 2 & 50 & 12 & 6 & 50 & 73 & 1 & 0 & . & 1 & 0 & \\
\hline Tota & & 17. & 2. & & 8.3 & 4. & & 3.2 & 2. & & 5.6 & 2. \\
\hline 1 & 7 & 29 & 93 & 24 & 3 & 36 & 4 & 5 & 06 & 3 & 7 & 08 \\
\hline
\end{tabular}

\section{Group 1 upper and lower median}

The h-index median of group 1 is 20.50 . The upper group includes only males, however no gender implications can be made since most of the initial group consisted of males. In order to identify age differences for the h-index in the lower median group, an ANOVA test was performed. No statistically significant difference was found due to the distribution, where 5 of the 7 people are in the older age group and 1 in each of the other two groups. The older age group has a higher h-index mean.

In order to identify age differences for the h-index in the lower median group, an ANOVA test was performed. A statistically significant difference was indeed found $(F(2,4)=12.19, p<.05)$. Since the younger age group had only one person, no post-hoc test could be performed. Therefore, we performed a t-test on the second and third (oldest) age groups, which showed 
a statistically significant difference $(t(4)=4.93, p<.01)$. In Table 5 we observe that the second age group has 4 people and a higher mean than the third oldest group. These results indicate that there are 2 people in the older age group, the group which in general is leading with the highest h-index, which hinders the group's general h-index, showing that although the older age group are the most productive, there are some exceptions.

\section{Group 2}

The upper median of the h-index includes 14 people. An ANOVA test was employed to examine age differences, showing no statistically significant difference. Table 6 presents the h-index per role for the upper and lower median of group 2 .

A t-test was employed to examine gender differences; however, none was found for both the lower and upper median group. We can however observe that the lecturer's rank and experts (senior lecturer expert and associate professor experts) exist only in the lower median group, meaning that they lower the general h-index mean of the entire group.

Table 6. Group 2 upper and lower median roles per h-index

\begin{tabular}{|c|c|c|c|c|c|c|}
\hline & \multicolumn{2}{|c|}{$\begin{array}{ll}\text { Group } & 2 \\
\text { median } & \end{array}$} & lower & \multicolumn{2}{|c|}{$\begin{array}{l}\text { Group } \\
\text { median }\end{array}$} & uppe \\
\hline & $N$ & Mean & $S D$ & $N$ & Mean & $S D$ \\
\hline Lecturer & 2 & 4.50 & 0.71 & & & \\
\hline Senior Lecturer & 4 & 9.25 & 2.99 & 2 & 19.50 & $\begin{array}{l}1 \\
3.5\end{array}$ \\
\hline Associate Professor & 7 & 8.43 & 3.82 & 10 & 19.70 & $\begin{array}{l}0 \\
10\end{array}$ \\
\hline Full Professor & 5 & 9.20 & 5.76 & 11 & 24.91 & 36 \\
\hline Senior Lecturer expert & 2 & 2.00 & 1.41 & . & . & \\
\hline $\begin{array}{l}\text { Associate Professor } \\
\text { expert }\end{array}$ & 4 & 11.25 & 3.50 & & & \\
\hline Total & 24 & 8.33 & 4.36 & 23 & 22.17 & \\
\hline
\end{tabular}

Group 3 and group 4

After removing the researchers with the lower median in the h-index (the median is 7 and 8 for groups 3 and 4, respectively), there were too few to reach any statistical inference for the age subgroups, as well as any difference 
in the roles. Table 7 presents the role distribution per h-index for the two subgroups of group 3. Similarly, group 4 consists of 5 people, therefore no statistical inference can be made for dividing it into subgroups.

\section{Discussion}

We examined the research output of faculty members who constitute the management spine of an academic institution. For this purpose, we divided the faculty into four groups by seniority and responsibility levels in the institution: President, Rector, and Deans; Heads of Department; faculty members operating in academic committees; and program heads, track heads, and deputy department heads. In addition, based on the research literature that relates to research output as dependent on gender and age, these two were explored in our study as well regarding the issue of research output of senior academic officials in an academic institution.

It may be concluded that the research findings indicate that the first group has the highest h-index, followed by the second group, and finally - the third and fourth groups. With regard to gender - no conclusions can be reached, as almost all those in this group are men. This finding might show that in 2020 , in the early third decade of the $21^{\text {st }}$ century, the management spine of an academic institution is still comprised, almost exclusively, of men. This despite awareness of the issue in all branches of management and academia in particular, and although the CHE encourages the integration of women in academic administration.

With regard to age - the group of retirees has the highest output. Has academia in Israel and elsewhere managed to integrate "retirees" as mentors of young researchers, supervisors for Master's and $\mathrm{PhD}$ theses, while recognizing their contribution - in a world with a rising life expectancy? And in general - how is age-associated with the academic output?

Notably, age and gender do not affect have any the h-index regarding academic output. The research findings indicate that with the degree of responsibility required for the role, the output of faculty members in this role rises as well. In addition, there is significance for "mentors" in academia, for those with a medium and low output. A type of "role model" by the "management spine" as researchers may be significant. Academic leadership is significant, and its meaning is manifested in the management spine.

The low number of women in managerial spine is notable. Eckhaus and Davidovich (2018) argue that the low number of women among senior academic faculty, is a global problem. While the are more females studying advanced academic degrees, but the rate of women among the faculty drops sharply. This may be partly due to the fact that the academic world encourages researchers to occupy a post-doctoral position in a different institution than 
where they earned their $\mathrm{PhD}$ and this requires mobilizing the entire family which is more difficult for women.

The fact that the management spine has the highest research output has the potential to illuminate the management profile of the academic institution. Academic management is unique for being two-headed, with a separation between academic management and administrative management. The research findings raise the question of whether and to what degree are considerations taken into account in policymakers' decisions academic or are administrative considerations dominant. This fact might have significance for decisionmaking processes in the institution - whether the attitude is based on the needs of academia or business motivations.

This study focuses on a critical question in the academic world concerning academic background of the managerial spine, which in practice affects both the quality of teaching and the quality of research. For instance, a managerial orientation would be to expand the number of students in the course versus stressing the quality of education that would be directed at reducing the number of students. Another example that often arises in the academic world is the weight given to student teaching surveys. Namely, in many institutions, the teaching quality of faculty members is measured by student satisfaction, i.e., a managerial orientation of client satisfaction rather than the actual quality of the teaching. On the research dimension, it is possible to take as an example the stimulation and weight given in academic institutions to the quantity of publications due to the funding provided based on this output, which comes of course at the expense of research quality that requires time for performance and depth. The greater the academic institution's emphasis on the business dimension, the lower its quality - both in teaching and in research. The business conception is of course, fundamental, and this orientation must be represented in the management spine of all institutions. However, this orientation must be balanced by a management representation with an academic background, one that understands the meanings and implications of decisions from an applied direction in the academic world.

The radicalization of the business orientation might eventually lead to a situation where an academic institution will not differ much from business firms that operate professional courses, and it will no longer be needed. Hence, the business orientation that strives for maximal profit is doing itself a disservice and will bring about the elimination of the institution. This study presents a more efficient state of affairs on the academic level of a managerial spine that presents academic outputs and thus serves as a role model for the faculty members it manages and leads. Nothing, however, is static, people are replaced, and the orientation may change. In summary, we propose that institution heads consider the haphazard attitude involved in the increasing tendency to push academic institutions towards the business dimension and 
that they make an effort to maintain the academic quality that has many implications for the younger generation studying at these establishments.

\section{References:}

1. Almog, T. \& Almog, A. (2020). All the lies of academia. Tel Aviv: Yedhiot Sfarim. [Hebrew]

2. Apkariana, J., Mulligan, K., Rotondi, M., \& Brint, S. (2014). Who governs? Academic decision-making in U.S. four-year colleges and universities, 2000-2012. Tertiary Education and Management, 20(2).

3. Babineau, M., Fischer, C., Volz, K., \& Sanchez, L. D. (2014). Survey of publications and the h-index of academic emergency medicine professors. Western Journal of Emergency Medicine, 15(3), 290-292.

4. Blumenstyk, G. (2015). American higher education in crisis? What everyone needs to know. Oxford University Press.

5. Brint, S. (2018). Two cheers for higher education: Why American universities are stronger than ever and how to meet the challenges they face (pp. 261-262). Princeton University Press.

6. Eckhaus, E., \& Davidovitch, N. (2018). Impact of gender and conference size on conference preferences - Employing natural language processing. International Journal of Educational Methodology, 4(1), 45-52. doi: 10.12973/ijem.4.1.45

7. Davidovitch, N., \& Eckhaus, E. (2018). Effect of faculty on research cooperation and publication: Employing natural language processing. Economics and Sociology, 11(4), 173-180. doi:10.14254/2071789X.2018/11-4/11

8. Davidovitch, N., \& Eckhaus, E. (2019a). Advantages of employment after retirement - a content analysis approach. What is academic professional experience worth after retirement age? World Journal of Education, 9(6), 65-73.

9. Davidovitch, N., \& Eckhaus, E. (2019b). Student evaluation of lecturers - what do faculty members think about the damage caused by teaching surveys? Higher Education Studies, 9(3), 12-21. 
10. Davidovitch, N., \& Eckhaus, E. (2019c). Teaching students to think faculty recommendations for teaching evaluations employing automated content analysis. International Journal of Higher Education, 8(3), 83-93.

11. Davidovitch, N., \& Eckhaus, E. (2020). The attitude of academic faculty to continued work by faculty members after reaching retirement age. Economics \& Sociology, 13(2), 123-135.

12. Eckhaus, E., \& Davidovitch, N. (2019a). Effect of personal and occupational characteristics on attitudes to an obligatory retirement age - a content analysis investigation. Journal of Education and Learning, 8(6), 169-179.

13. Eckhaus, E., \& Davidovitch, N. (2019b). How do academic faculty members perceive the effect of teaching surveys completed by students on appointment and promotion processes at academic institutions? A case study. International Journal of Higher Education, 8(1), 171-180.

14. Eckhaus, E., \& Davidovitch, N. (2019c). Potential for blocking advancement: teaching surveys for student evaluation of lecturers. International Journal of Educational Methodology, 5(3), 401-406.

15. Eckhaus, E., \& Davidovitch, N. (2020). The changing of the guard in academia and academic research leadership--employing natural language processing. International Education Studies, 13(8), 95-102.

16. Eckel, P. D. \& Trower, C. A. (2018). Practical wisdom: Thinking differently about college and university governance. Stylus Publishing.

17. Hearn, A. \& Brown, V. (2016). Lessons from the eye of the storm: Chakmagate and Western University. Academic Matters.

18. Hirsch, J. E. (2007). Does the $h$ index have predictive power? Proceedings of the National Academy of Sciences, 104(49), 1919319198.

19. Hodge, D. R., \& Lacasse, J. R. (2011). Evaluating journal quality: is the h-index a better measure than impact factors? Research on Social Work Practice, 21(2), 222-230.

20. Hofstadter, R. (1955). The development of academic freedom in the United States. Columbia University Press.

21. Jahic, H. \& Rahimic, A. (2017). We don't need no education - Bosnia and Herzegovina's higher education reform. FutureLab Europe.

22. Kaplan, G. E. (2002). Preliminary results from the 2001 Survey on Higher Education Governance. The American Association of University Professors \& The American Conference of Academic Deans.

23. Nelson, S. J. (2014). College presidents reflect: Life in and out of the ivory tower. Rowman \& Littlefield Publishing Group. 
24. Santiago, P., Tremblay, K., Basri, E. \& Arnal, E. (2008). Tertiary education for the knowledge society. Volume 1: Governance, funding, quality. OECD.

25. Skúlason's, P. (2015). A critique of universities. University of Iceland Press.

26. Stewart, G. (2016). Editor matters: Whose university is it anyway? Academic Matters.

27. Councilt of Higher Education. (2012). The Movement for Quality Government in Israel. Higher education - low transparency. Department of Economics and Research. [Hebrew]

28. Trachtenberg, S. J., Kauver, G. B. \& Bogue, E. G. (2016). Presidencies derailed: Why university leaders fail and how to prevent it. Johns Hopkins University Press.

29. Waldo, D. (1970). The university in relation to the governmental political. In: C. J. Wingfield, (Ed.). The American University : A public administration perspective (pp. 19-31). Southern Methodist Univ. 